\title{
Book review: Psychology and the Study of Education: Critical perspectives on developing theories, edited by Cathal Ó Siochrú
}

\section{Emma Swift iD}

\section{How to cite this article}

Swift, E. (2020) 'Book review: Psychology and the Study of Education: Critical perspectives on developing theories, edited by Cathal Ó Siochrú'. London Review of Education, 18 (1): 145-147. https://doi.org/10.18546/LRE.18.1.11

Submission date: 24 April 2019

Acceptance date: 3 May 2019

Publication date: 1 March 2020

\section{Peer review}

This article has been through editorial review.

\section{Copyright}

(C) Copyright 2020 Swift. This is an Open Access article distributed under the terms of the Creative Commons Attribution Licence (CC BY) 4.0 https://creativecommons.org/licenses/by/4.0/, which permits unrestricted use, distribution and reproduction in any medium, provided the original author and source are credited.

\section{Open access}

London Review of Education is a peer-reviewed open-access journal. 


\section{Book review}

Emma Swift* - Manchester Metropolitan University, UK

Psychology and the Study of Education: Critical perspectives on developing theories, edited by Cathal Ó Siochrú

Abingdon: Routledge; 2018; 184 pp., ISBNs: 978-1-13823-765-0 (pbk); 978-1-13823-764-3 (hbk); 978-1-31529-935-8 (ebk)

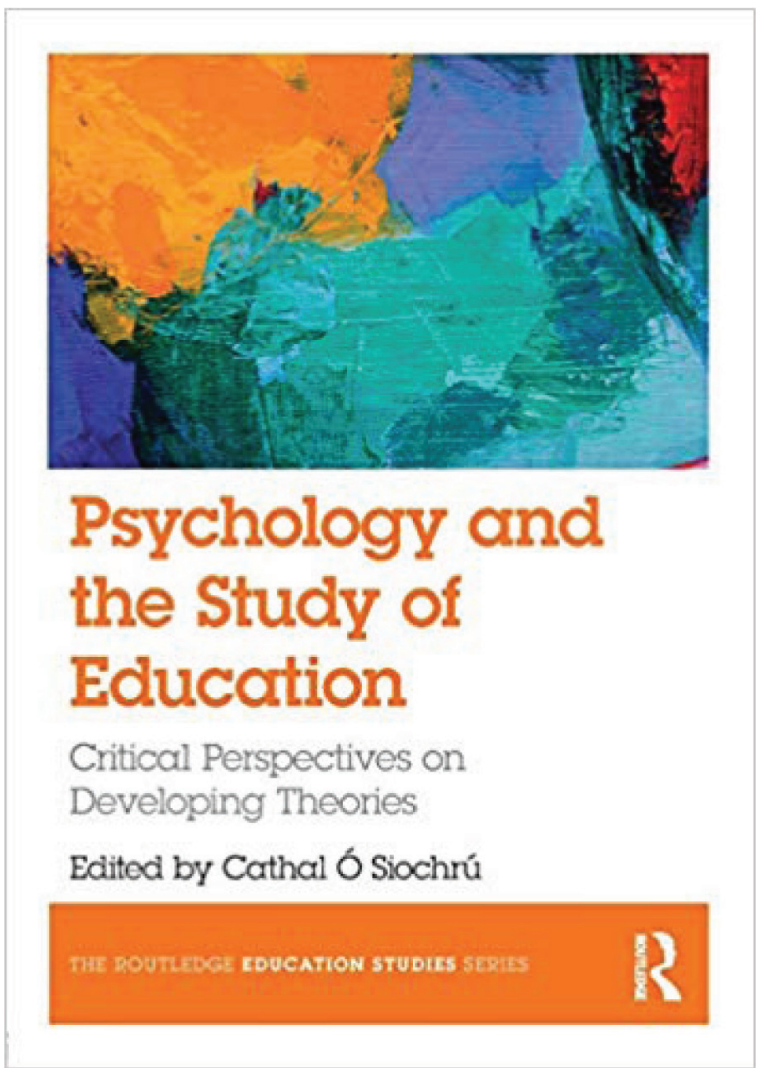

Educational psychology has seen a rise in popularity in recent years, and it is vital that those working in the education sector, or within the psychology discipline, appreciate its importance. Psychology and the Study of Education: Critical perspectives on developing theories, edited by Dr Cathal Ó Siochrú, a senior lecturer in the psychology of education at Liverpool Hope University, champions this notion. I feel that within such a short review it is difficult to discuss each chapter separately, and therefore have provided a general overview and reflected upon key components pertinent to myself. The textbook is well comprised, with a number of insightful chapters where psychological theory is applied to real-world educational contexts. The chapters are authored by notable academics within the fields of education and psychology, and are written in a cheerful and charismatic style. Many anecdotal examples are provided, 
and this gives the book a refreshing twist. The chapters are further enhanced with discussion of a number of key influential figures and their research, such as Wilhelm Wundt, Edward Thorndike, Bandura, Piaget, Vygotsky and Watson. There are three main sections: Part One focuses on 'Processes: An exploration of key learning processes' (11); Part Two is entitled 'Identities: Examining the role of the mind and identity in learning' (67); Part Three concludes the book by discussing 'Origins: Re-examining some of the core theories of learning' (123). It is useful that the text is divided into these particular sections, and one assumes that students would find the book easy to navigate to access the information they require.

The intended audience is those with a small amount of prior psychology knowledge, seeking to gain greater insight into the psychology of education. The book is recommended for those studying or teaching on education studies, childhood and youth studies, disability studies or teacher training degree programmes, and would be a great resource to add context to the way in which psychology complements education. Insights from contemporary studies conducted in both psychology and education are provided, while substantiating how key classic studies have shaped the fields. The reader is invited to question the importance psychology can have in explaining educational concepts and in shaping its future, and is aided by useful reflection boxes. This process actively encourages critical thinking and analysis, and as a lecturer, I appreciate the importance of this skill for any undergraduate student. The message reinforced throughout is that education and psychology go hand in hand and enrich each other perfectly.

Chapter 1 (Ó Siochrú) is particularly prominent and lays solid foundations for subsequent chapters; it instantly engages the reader, and intuitively makes them consider their own perceptions of education. It gently introduces what is considered by the term education, and how psychologists view the concept of learning. There is an immediate acknowledgement that learning is far greater than the process that takes place within the classroom, and it is pleasing to see this highlighted from the outset. A clear and thought-provoking definition of education and the role of an educator is also provided. These two terms are summarized as:

an event or process which has been organised with the explicit purpose of producing learning in those that participate in it and we define an educator as a role whose primary purpose is to promote and facilitate the education of others. (2)

The discipline of psychology is introduced and described as the 'scientific study of behaviour' (3), recognizing the tribulations it had in establishing itself as a science. It is great to see throughout the entire book that evidence and background information is presented in a style that allows readers to draw their own conclusions and judgements. This positions the book well with the view that 'there are no theories in psychology on which all psychologists agree, which are universally applicable or which are immune to be challenged or changed' (5).

A number of interesting factors surrounding creative learning are considered in Chapter 3 (Yeh), which aims to question and counteract 'common views on the nature of creativity and to make the case for the role of education in enhancing an individual's creative potential' (31). Two factors, 'defocused (broadened) attention' (35) and 'emotions' (37), said to influence creativity, are discussed. However, the information surrounding attentional breadth may be somewhat difficult for an undergraduate student with minimal knowledge of psychology to comprehend, and a greater number of examples as displayed in other chapters may have facilitated a better understanding. 
This is evidenced in statements such as 'This shift in visual attentional breadth could subsequently engender a corresponding shift in internal breadth of conceptual attention, increasing or undermining cognitive generation correspondingly' (36). While it is important to challenge students, given the target audience, some of the information presented in this section could be considered a little opaque and verbose for those in the early stages of learning about the discipline.

Although many of the core areas of psychology are neatly embedded and interwoven throughout, it may have been beneficial to state and introduce the area or areas of psychology with which a topic specifically corresponds. For example, a reader with minimal psychology knowledge may not instantly be able to identify that 'Memory and learning' (Chapter 2, Egan) are related to aspects of cognitive psychology, and that 'Learning to relate' (Chapter 6, Stack) refers to aspects of social psychology, such as relationships and behaviour. In addition, given the nature of the book, I expected a greater focus on the concept of intelligence. However, I did find the short section on the 'IQ discrepancy method' (60) in relation to dyslexia particularly insightful.

In my opinion, Chapter 2 on 'Memory and learning' (Egan) stood out as an excellent and informative read. It presented, in chronological order, how research surrounding memory has developed, and provided information on the multi-store model of memory (Atkinson and Shiffrin, 1968), and the later progressions by Baddeley and Hitch (1974). These were explained thoroughly before applying them to real-world situations, such as how memory can be improved. However, it may have been useful to display a pictorial representation of each model, to enable the reader to better visualize the different components, and how they fit together. The chapters contained in Part Three further accentuate the text, as they provide new insight by delving critically into key learning theories. Particular focus is placed upon Piaget's theory of cognitive development (Chapter 8, Lloyd), behaviourism (Chapter 9, Ó Siochrú), and 'Vygotsky and socio-cultural theories of learning' (Chapter 10, O'Connell).

It should be noted that this textbook is not a comprehensive journey through educational psychology, nor does it claim to be. What it does do, however, is select the highlights of both disciplines and evidence to its readers the importance of understanding how they harmonize with each other. Although the intended target audience is those teaching or studying on an education study-related degree, the book should be considered as a great addition to any first-year educational psychology degree reading list, or any British Psychological Society (BPS) conversion master's. The book contextualizes and explains learning and education using key psychological theory and principles, and is an excellent and valuable introduction for any student.

\section{References}

Atkinson, R.C. and Shiffrin, R.M. (1968) 'Human memory: A proposed system and its control processes'. In Spence, K.W. and Spence, J.T. (eds) The Psychology of Learning and Motivation: Advances in research and theory (Vol. 2). New York: Academic Press, 89-195.

Baddeley, A.D. and Hitch, G. (1974) 'Working memory'. In Bower, G.H. (ed.) The Psychology of Learning and Motivation: Advances in research and theory (Vol. 8). New York: Academic Press, 47-89. 